\title{
Breast Cancer Screening Program in Stockholm County, Sweden - Aspects of Organization and Quality Assurance
}

\author{
Helena Lind ${ }^{a} \quad$ Gunilla Svane $^{\mathrm{b}} \quad$ Levent Kemetli $^{\mathrm{a}} \quad$ Sven Törnberg $^{\mathrm{a}}$ \\ ${ }^{a}$ Department of Cancer Screening, Oncologic Centre of Stockholm-Gotland, Karolinska University Hospital and Karolinska Institute, \\ ${ }^{b}$ Department of Diagnostic Radiology, Karolinska University Hospital, Stockholm, Sweden
}

\section{Key Words}

Breast cancer screening program · Organization . Quality assurance

\section{Summary}

The population-based breast cancer screening program in Stockholm County was initiated in 1989. The program follows the recommendations issued by the Swedish Board of Health and Welfare, and is in agreement with guidelines from the European Commission. Individual data is available for all women in Stockholm County aged 40-69 years since initiation of the program in 1989. The participation rate exceeds $70 \%$, the recall rate averages $3 \%$, and the detection rate is $0.5 \%$. The introduction of the breast cancer screening program in Stockholm County has reduced breast cancer mortality by $29 \%$ and among participants by $52 \%$. The breast screening program is well organized and functioning, and well adapted to its purpose. Follow-up ensures a good quality process with the aim of reducing breast cancer mortality.

\section{Introduction}

Breast cancer is the most common malignancy in Swedish women [1]. In 2008, 7,301 new cases were diagnosed of whom 1,456 were living in the County of Stockholm. In 2007 1,477 Swedish women died from breast cancer, and 277 of these women lived in Stockholm [2]. The aim of the breast cancer screening program is to find cancer early and in a curable phase in order to decrease mortality caused by breast cancer. The ideal result of a screening program is reduced suffering

\section{Schlüsselwörter}

Brustkrebsvorsorgeprogramm · Organisation . Qualitätskontrolle

\section{Zusammenfassung}

Das bevölkerungsbasierte Brustkrebsvorsorgeprogramm in der Provinz Stockholm wurde 1989 ins Leben gerufen. Das Programm basiert auf Empfehlungen der Schwedischen Behörde für Gesundheit und Sozialwesen in Übereinstimmung mit den Richtlinien der Europäischen Kommission. Individuelle Daten sind verfügbar zu allen 40-69-jährigen Frauen in der Provinz Stockholm seit dem Beginn des Programmes in 1989. Die Teinahmerate übersteigt $70 \%$, die Wiederaufrufsrate beträgt im Durchschnitt 3\%, und die Nachweisrate ist 0,5\%. Die Einführung des Brustkrebsvorsorgeprogramms in der Provinz Stockholm hat die Brustkrebsmortalität insgesamt um $29 \%$ und unter den Teilnehmerinnen um 52\% gesenkt. Das Brustkrebsvorsorgeprogramm ist gut organisiert und funktionsfähig, und ist seinem Zweck gut angepasst. Follow-up gewährleistet die gute Qualität des Progammablaufs mit dem Ziel der Verminderung der Brustkrebsmortalität.

for the affected individual at the minimum cost for society. High coverage and regular attendance are necessary to achieve this aim and can only be obtained by trust and acceptance among the targeted population [3]. In 1986, the Swedish National Board of Health and Welfare (SNBHW) issued recommendations for the Swedish County Councils to initiate a breast cancer screening program for women aged 40-74 years [4]. The recommendations were based on the results of the Two-County study published in Lancet in 1985, which showed a $31 \%$ reduction in mortality among participating

\section{KARGER}

Fax +497614520714

Information@Karger.de

www.karger.com (c) 2010 S. Karger GmbH, Freiburg

Accessible online at:

www.karger.com/brc 
women [5]. The Malmö Mammography Screening trial published in the British Medical Journal 1988 did not achieve the same cancer mortality reduction as did the Two-County study, especially not in younger women [6]. This resulted in altered recommendations from the SNBHW to primarily focus on women aged 50-69 years. Accordingly, Stockholm County Council decided to initiate a mammography screening program for breast cancer, which was launched in July 1989 [7]. More recent research has shown a favorable effect also in the younger age groups [8], and since July 2005 women aged 40-49 years have also been included in the screening program. The SNBHW issued new recommendations in 1998 [9].

\section{Material and Methods}

The screening program is currently carried out in 5 screening units, each responsible for 1 of the 5 catchment areas within Stockholm County. Four of the units were enrolled in the screening program in 1989, and the fifth in 1990. Danderyds University Hospital and Karolinska University Hospital each have approximately 60,000 women aged 40-69 years, S:t Görans Hospital and Tumba each have around 70,000 women, and the Stockholm South General Hospital is accountable for almost 100,000 women. There are plans to expand the program to include also women aged 70-74 in 2013, which will add another 30,000 women to the program.

As a routine a two-view mammography is made at the first round, and a one-view mammography at subsequent rounds. Digital mammography has gradually been introduced since April 2006 and was fully implemented in August 2008. All mammograms are read by two independent radiologists in each unit. At the start, participation was free of charge, but a fee was introduced in 1993 and amounts to 140 SEK (15 €) in 2010. The 5 units have a local booking system with online connection to the daily updated regional population register. Linkage between the population register is possible through the unique Swedish personal identification number. The target population consists of all women aged 40-69 years who have a personal identification number and a postal address within Stockholm County. The units send out letters of invitation offering an individual appointment time which can be re-scheduled by phone, letter, or email. Age group 50-69 years is invited every 24 months and age group 40-49 years every 18 months. Women attending mammography outside the screening still get invited to the official screening program. Due to a new administrative system which was introduced in 1999, reminders are no longer sent to those who did not attend a scheduled appointment without cancellation. These women are registered as 'passive' non-participants. A new invitation is sent according to the intervals decided by the age of the woman. A woman can request to receive no further invitations and is registered as an 'active' non-participant.

Following a normal mammogram, a letter with the results is sent to the individual within 2 weeks. In the case of any pathological findings, the woman is recalled usually within 1 week for additional radiographic and clinical assessments. If the additional radiological examinations are normal and there are no symptoms or signs from the breasts, there will be no more tests and the woman re-enters the screening program. If an abnormality or malignancy is diagnosed, a needle biopsy is performed. If malignancy cannot be ruled out, a multidisciplinary conference including radiologists, surgeons, cytologists, pathologists, and oncologists, is held to decide on further diagnostic assessments or additional examinations and treatment. A woman can at any stage of the process choose to decline further examinations or treatments.

In the SNBHW's recommendations for the breast cancer screening program of 1986, there are recommendations on items for follow-up and quality assurance. The Department of Cancer Screening at the Stockholm
Oncologic Centre is assigned to administrate the coordination and followup of the breast cancer screening program in order to ensure a coherent screening process of good quality. The staff presently includes physicians, nurses, administrators, system administrator, and statisticians. A flow chart of the breast cancer screening program is presented in figure 1. Measures of attendance, findings at radiological examinations, clinical examination, cytological findings, type of surgery, histopathological results as well as dates from the screening program are registered (table 1). Data on breast cancer screening in Stockholm County has been stored in a data base since the initiation of the program in 1989. The same body of data is analyzed to detect any differences in trends. The dates are used for calculations of lead times (table 2) between the examinations and crucial events in the medical care. The department also performs research in effect measuring, i.e. reduction of breast cancer mortality. A steering committee for quality assurance consisting of mammography radiologists, surgeons, oncologists, nurses, technicians, statisticians, and others working in the field meets twice a year. The aim is to monitor statistics and lead times and to discuss other aspect and issues involved in the field.

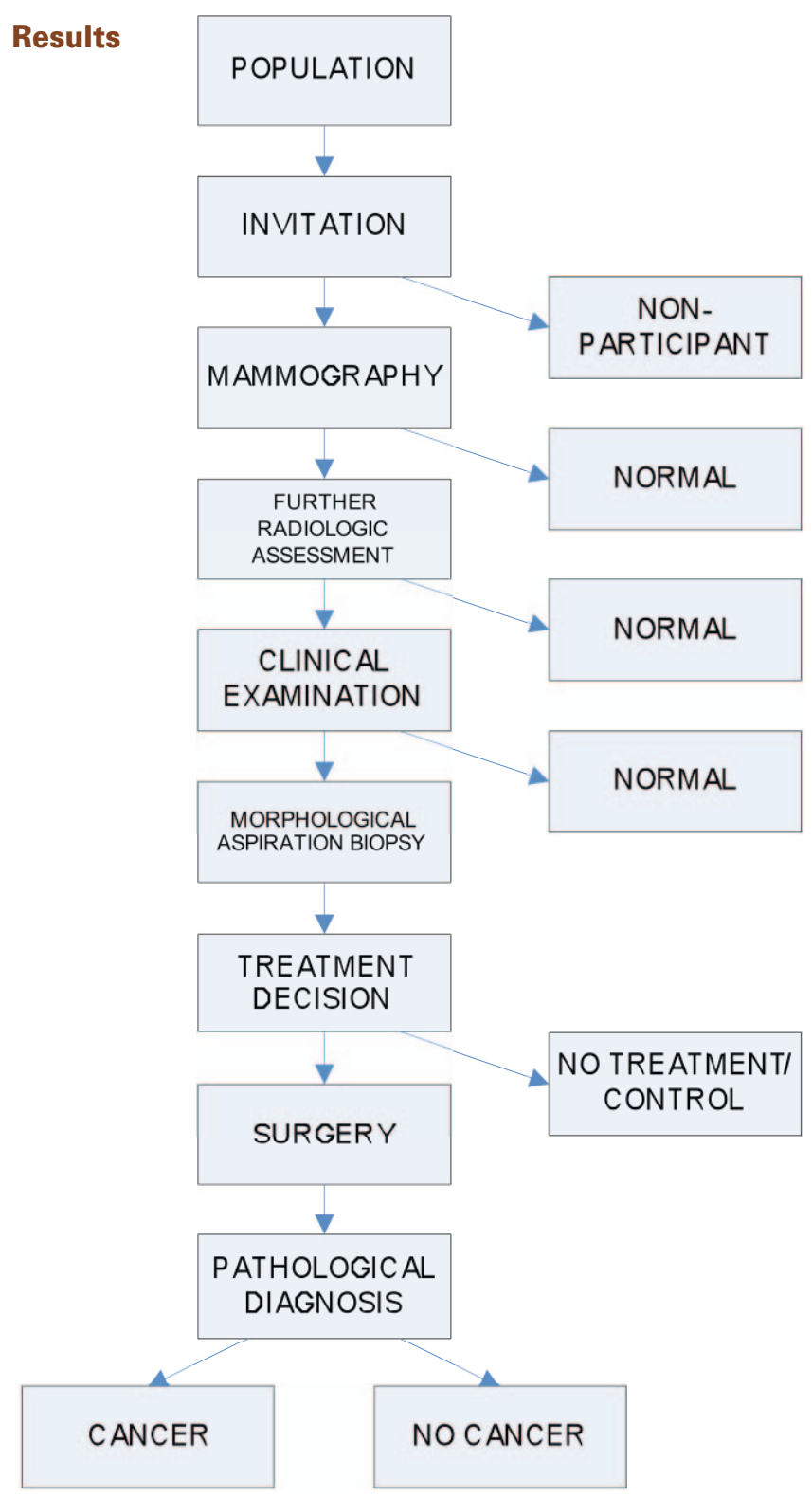

Fig. 1. Flow chart of the Stockholm County Breast Cancer Screening Program. 
Table 1. Registered results from the Stockholm County Breast Cancer Screening Program

\begin{tabular}{|c|c|c|}
\hline Status of breast cancer screening & invited & $\begin{array}{l}\text { participant, date } \\
\text { non-participant active/ } \\
\text { non-participant passive }\end{array}$ \\
\hline \multicolumn{3}{|l|}{ Mammography } \\
\hline Not recalled & technical problems & normal mammography \\
\hline Recalled & selected & due to mammography/clinical status \\
\hline Results of routine mammography & mammography diagnosis, code & $\mathrm{I}-\mathrm{V}$ \\
\hline Summary of complete radiological examinations & $\begin{array}{l}\text { radiological diagnosis, code } \\
\text { unilateral or bilateral findings }\end{array}$ & $\begin{array}{l}\mathrm{I}-\mathrm{V} \text {, date } \\
\text { woman declines further examinations }\end{array}$ \\
\hline \multicolumn{3}{|l|}{ Clinical examination } \\
\hline Reason for clinical examination & pathological findings on mammography/due & $\mathrm{I}-\mathrm{V}$, date \\
\hline Results of clinical examinations & $\begin{array}{l}\text { to clinical status } \\
\text { clinical diagnosis, code }\end{array}$ & woman declines further examinations \\
\hline \multicolumn{3}{|l|}{ Cytological aspiration biopsy } \\
\hline Results from cytological aspiration biopsy & $\begin{array}{l}\text { manual } \\
\text { stereotactic guidance } \\
\text { ultrasound guidance } \\
\text { cytological diagnosis, code }\end{array}$ & $\mathrm{I}-\mathrm{V}$, date \\
\hline \multicolumn{3}{|l|}{ Treatment decision } \\
\hline & $\begin{array}{l}\text { no treatment } \\
\text { control } \\
\text { diagnostic biopsy } \\
\text { definitive treatment }\end{array}$ & $\begin{array}{l}\text { date } \\
\text { woman declines treatment }\end{array}$ \\
\hline \multicolumn{3}{|l|}{ Surgery } \\
\hline & $\begin{array}{l}\text { ablatio and axillary nodes } \\
\text { ablatio without axillary nodes } \\
\text { partial resection and axillary nodes } \\
\text { partial resection without axillary nodes } \\
\text { open biopsy } \\
\text { other } \\
\text { Sentinel node } \\
\text { not operable }\end{array}$ & \\
\hline \multicolumn{3}{|l|}{ Histological results and staging } \\
\hline Tumor size & metastases no & $\mathrm{mm}$ \\
\hline Resected axillary lymph nodes, $\mathrm{n}$ & metastases yes & axillary lymph node metastases, $\mathrm{n}$ \\
\hline pTNM stage & LCIS* & stage 0 \\
\hline \multirow{8}{*}{ Distant metastases } & $\mathrm{DCIS}^{\dagger}$ & stage 0 \\
\hline & invasive cancer & stage I-IV \\
\hline & invasive cancer + DCIS & \\
\hline & multifocal cancer & I-III \\
\hline & $\mathrm{PAD}^{\ddagger}$ & anatomic location \\
\hline & $\mathrm{PAD}$, grade & \\
\hline & & \\
\hline & yes & \\
\hline \multicolumn{3}{|l|}{ Screening units } \\
\hline Mammography units, $\mathrm{n}$ & equipment & $\begin{array}{l}1-5 \\
\text { analogue/digital }\end{array}$ \\
\hline Access to registers & $\begin{array}{l}\text { Swedish Population Registry } \\
\text { Cancer Registry } \\
\text { Cause of death Registry }\end{array}$ & \\
\hline $\begin{array}{l}\text { *Lobular Carcinoma in Situ } \\
\text { 'Ductal Cancer in Situ } \\
{ }^{*} \text { Pathological-Anatomical Diagnosis }\end{array}$ & & \\
\hline
\end{tabular}

In 2008, 154,270 women were invited to the breast cancer screening program in Stockholm County. The number of participants was 110,586 women giving a participating rate of $71.7 \%$. For a number of years, the average participation rate has been around $70 \%$ (fig. 2). In total, 2,911 of the partici- pants were recalled for further assessment in 2008, with a recall rate of close to $3 \%$. Over a longer period of time, an average of $3 \%$ of all participants have been recalled (fig. 3). Around $84 \%$ of the reassessments among attendees were made due to an atypical mammogram. Overall, $16 \%$ of the 
Table 2. Lead times from the Stockholm County Breast Cancer Screening Program

\begin{tabular}{ll}
\hline Lead time & \\
\hline from & to \\
\hline Screening date & cytology date \\
Screening date & surgery date \\
Screening date & pathology diagnosis date \\
Treatment decision date & surgery date \\
Surgery date & pathology diagnosis date \\
\hline
\end{tabular}

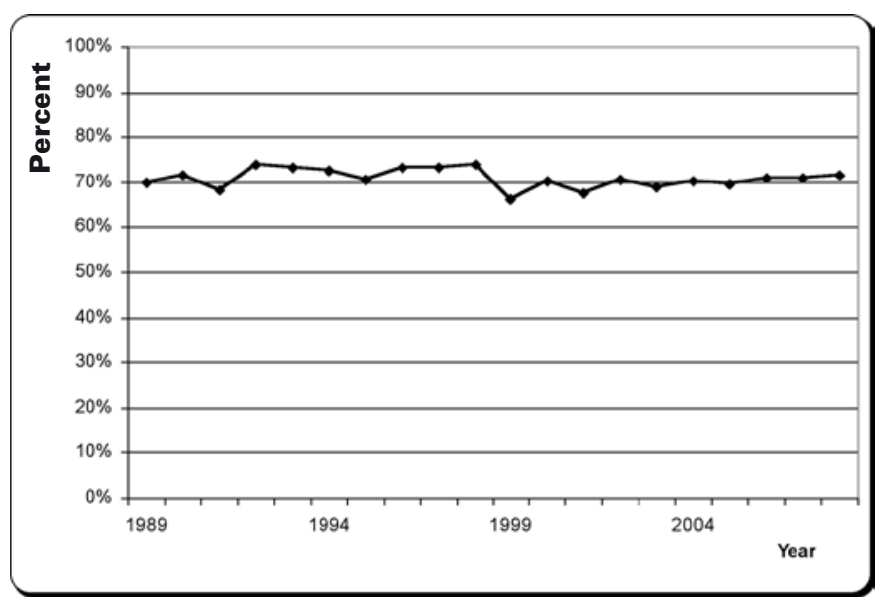

Fig. 2. Participation rate 1989-2008.

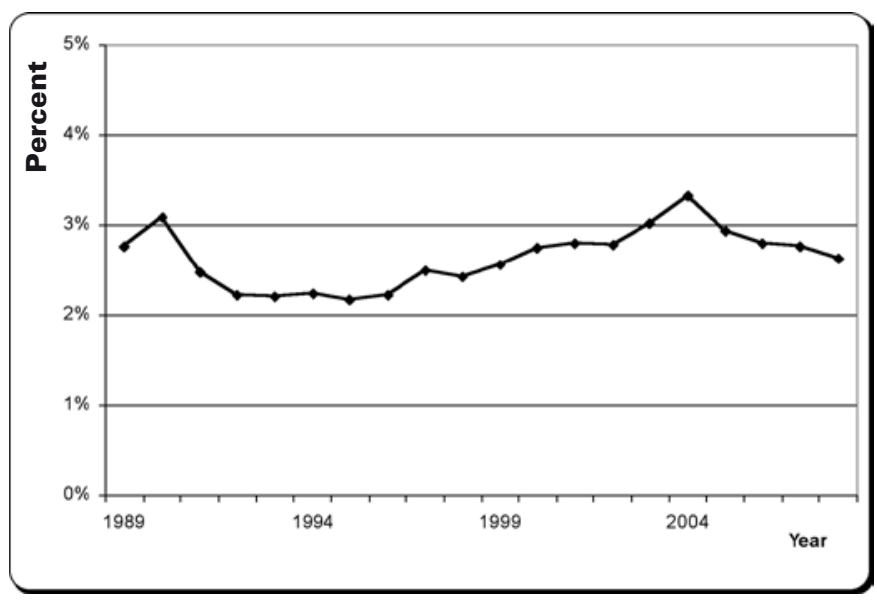

Fig. 3. Recall rate 1989-2008.

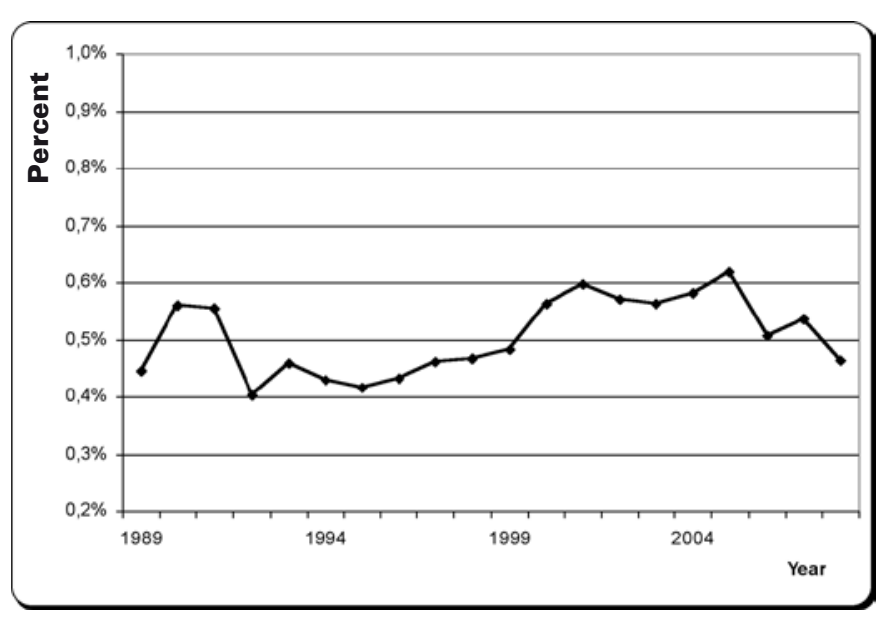

Fig. 4. Detection rate 1989-2008. reassessed were recalled because of the woman herself noticing something irregular in her breasts. Approximately $20 \%$ of the recalled were subjected to cytology needle aspirations. The proportion of ultrasound-guided biopsies has increased while stereotactic biopsies have decreased in recent years. The frequency of detection is the number of screened women who are diagnosed with breast cancer, which has been on average $0.5 \%$ (fig. 4 ).

\section{Discussion}

Over the years, there have been changes in the proportion of invited women, ranging from 91.4 to $100 \%$. A decrease occurred in 2000-2003, which possibly can be explained by difficulties in maintaining the invitation intervals in the screening units. The acceptance to invitations has also been subject to alterations over time. One of the units has always had a lower proportion of acceptance to the invitations due to access to privately organized health care measures including mammography prior to the introduction of the official breast cancer screening program in this part of Stockholm. Mammography performed outside of the screening program is not centrally reported, and the individual will still receive an invitation according to the set intervals, resulting in unnecessary administrative efforts for both the radiology booking staff and the woman in question. A small attendance decrease was noticed when a fee was introduced in 1993. Attendance was further decreased across the board by $10.5 \%$ when the reminders were discontinued in 1999. Negative studies and reports in the media may also have been responsible for this temporary fall in attendance figures. Research has shown that there is a higher probability of a woman attending a consecutive round if she had attended the previous one, irrespective of which round she attended for the first time. Having attended a screening examination once increased the likelihood of attending the subsequent rounds [10]. This is the reason for keeping on inviting passive non-participants.

The level of detection and the tumor stage give vital information on whether the screening program is on the 'right track'. A change in examination methods leading to alterations in sensitivity or specificity can suddenly change these parameters. Since the introduction of digital mammography, there has been a small increase in the proportion of cancer in situ. A higher resolution makes it easier to identify this type of abnormality on the mammogram. The proportion of breast cancer stage II+ has increased. One explanation could be more sensitive methods used for the pathological examination, but it could also be the result of a new method of lymph nodes resection, the sentinel node method. More lymph node metastases are found now when compared to previous types of surgery. The dates of examination as well as the date of the definitive treatment being decided on are important for calculating a number of lead times. Increases in lead times can be 
used to locate structural problems such as lack of adequate equipment and competent staff at an early stage.

In 2006, a study by the Swedish Organized Service Screening Evaluation Group was published. The study showed that the breast cancer screening program in Stockholm reduced breast cancer mortality by $29 \%$ in the target population. Among active participants, the reduction was even more pronounced with $52 \%$ [11]. Other studies have shown a reduction in breast cancer mortality of around $40 \%$ among women participating in breast cancer screening projects [12]. It is essen- tial to maintain a good quality, keep in line with current knowledge and science, improve ways of invitation and management of the mammography procedure, and finally inform health authorities and the public of results in order to reach the aim of decreasing mortality caused by breast cancer.

\section{Conflict of Interest}

The authors declare that they have no competing interests.

\section{References}

1 Cancer Incidence in Sweden. Stockholm, Swedish National Board of Health and Welfare, 2008.

2 Cause of Death Registry (Swedish). Stockholm, Swedish National Board of Health and Welfare, 2007

3 European Guidelines for Quality Assurance in Breast Cancer Screening and Diagnosis, ed. 4. Luxembourg, European Commission, 2006.

4 Mammographic Screening for Early Detection of Breast Cancer (Swedish); in Socialstyrelsen (ed) Stockholm, Swedish National Board of Health and Welfare, 1986.

5 Tabar L, Fagerberg CJ, Gad A, Baldetorp L, Holmberg LH, Grontoft O, Ljungquist U, Lundstrom B, Manson JC, Eklund G, et al.: Reduction in mortality from breast cancer after mass screening with mammography. Randomised trial from the breast cancer screening working group of the Swedish National Board of Health and Welfare. Lancet 1985;1:829-832.
6 Andersson I, Aspegren K, Janzon L, Landberg T, Lindholm $\mathrm{K}$, Linell $\mathrm{F}$, Ljungberg $\mathrm{O}$, Ranstam J, Sigfusson B: Mammographic screening and mortality from breast cancer: the Malmo mammographic screening trial. BMJ 1988;297:943-948.

7 Lidbrink EK, Tornberg SA, Azavedo EM, Frisell JO, Hjalmar ML, Leifland KS, Sahlstedt TB, Skoog L: The general mammography screening program in Stockholm. Organisation and firstround results. Acta Oncol 1994;33:353-358.

8 Moss SM, Cuckle H, Evans A, Johns L, Waller M, Bobrow L: Effect of mammographic screening from age 40 years on breast cancer mortality at 10 years' follow-up: a randomised controlled trial. Lancet 2006;368:2053-2060.

9 Hälsoundersökningar med mammografi, underlag för rekomendation om screening för bröstcancer (Swedish); in Socialstyrelsen (ed). Stockholm, Swedish National Board of Health and Welfare, 1998. SoS-rapport 1998:17.
10 Tornberg S, Kemetli L, Svane G, Rosen M, Stenbeck M, Nystrom L: Pattern of participation in a cohort aged 50-60 years at first invitation to the service-screening programme with mammography in Stockholm County, Sweden. Prev Med 2005;41:728-733.

11 SOSSEG, Duffy S, Tabar L, Chen T, Smith RA, Holmberg L, Jonsson H, Lenner P, Nystrom L, Tornberg S: Reduction in breast cancer mortality from organized service screening with mammography: 1. Further confirmation with extended data. Cancer Epidemiol Biomarkers Prey 2006;15:45-51.

12 Tabar L, Yen MF, Vitak B, Chen HH, Smith RA, Duffy SW: Mammography service screening and mortality in breast cancer patients: 20-year followup before and after introduction of screening. Lancet 2003;361:1405-1410. 